\title{
Rapid Fournier's gangrene diagnosis by ultrasound
}

\section{Greg Zahn}

67 yo $M$ presented to ED with groin pain / weakness; duration 2-3 days. Triage vitals: $37^{\circ} \mathrm{C}, \mathrm{BP} 81 / 59$, HR 102. PMH of CAD, OSA, Obesity, HTN. On exam, edema was noted without blisters or other skin abnormalities of the penis and scrotum. Edema isolated to penis and scrotum without surrounding involvement. Given delay with CT, bedside US was utilized and displayed dirty shadowing artifact consistent with air in the tissue (Fig. 1) concerning for necrotizing infection. In contrast, Fig. 2 displays normal soft tissue appearance of R scrotal tissue. Broad-spectrum antibiotics were started and specialist consulted. CT obtained for operative planning as patient transported to OR, confirming US diagnosis. US resulted in rapid diagnosis that greatly expedited definitive management.

This is the author's manuscript of the article published in final edited form as:

Zahn, G. (2019). Rapid Fournier's gangrene diagnosis by ultrasound. Visual Journal of Emergency

Medicine, 15, 100572. https://doi.org/10.1016/j.visj.2019.100572 


\section{References}

1. Stevens D.L., and Bryant A.E.: Necrotizing soft-tissue infections. N Engl J Med 2017; 377: pp. 22532265

2. Wong C.H., Khin L.W., Heng K.S., Tan K.C., and Low C.O.: The LRINEC (Laboratory risk indicator for necrotizing fasciitis) score: a tool for distinguishing necrotizing fasciitis from other soft tissue infections. Crit Care Med 2004; 32: pp. 1535-1541 
Fig. 1. Left scrotum. Multiple echogenic foci representative of air within the tissue identified with classic dirty shadowing artifact.

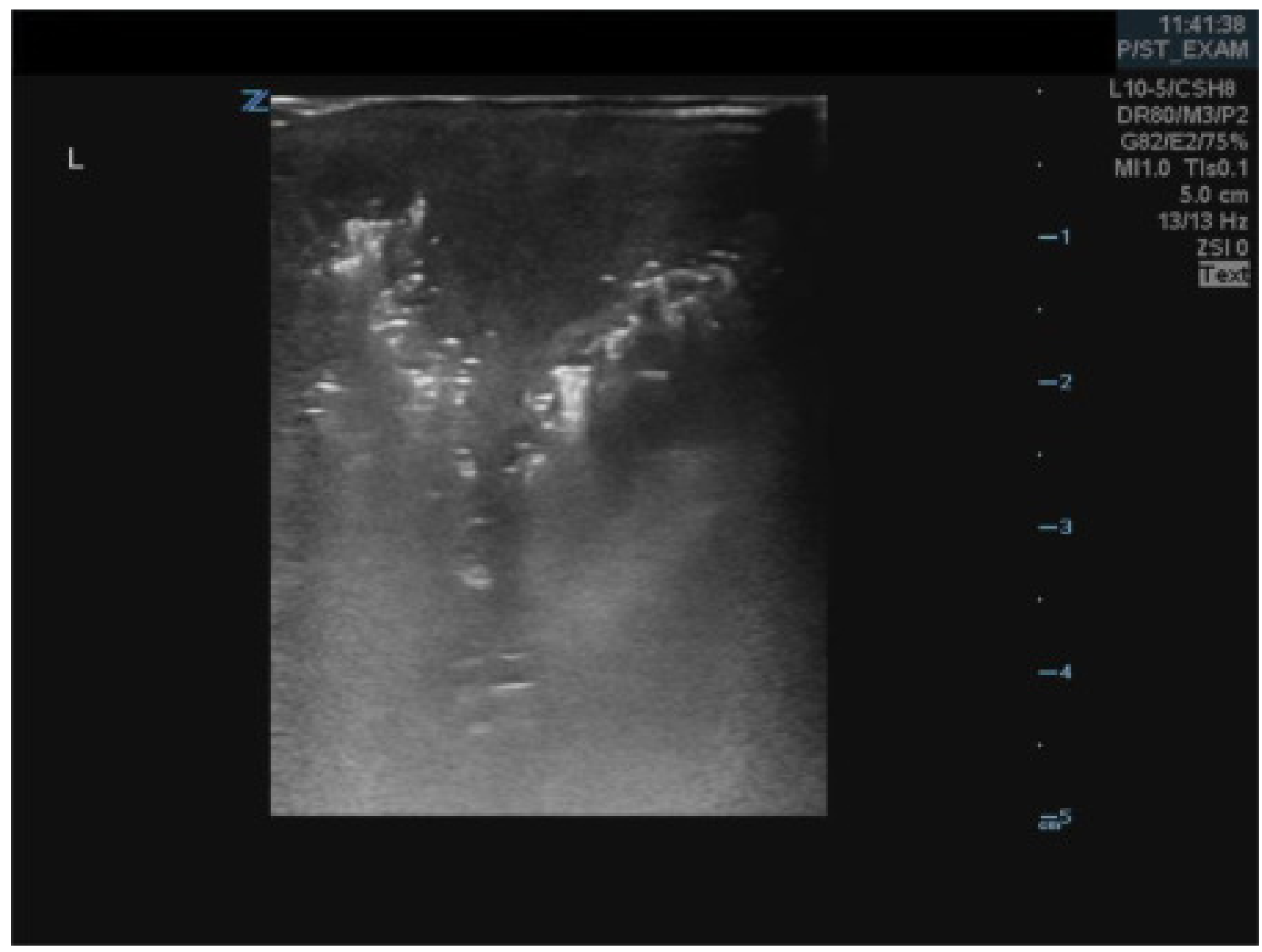


Fig. 2. Normal appearance of right scrotum. Able to visualize right testicle secondary to normal soft tissue of scrotum that doesn't contain air.

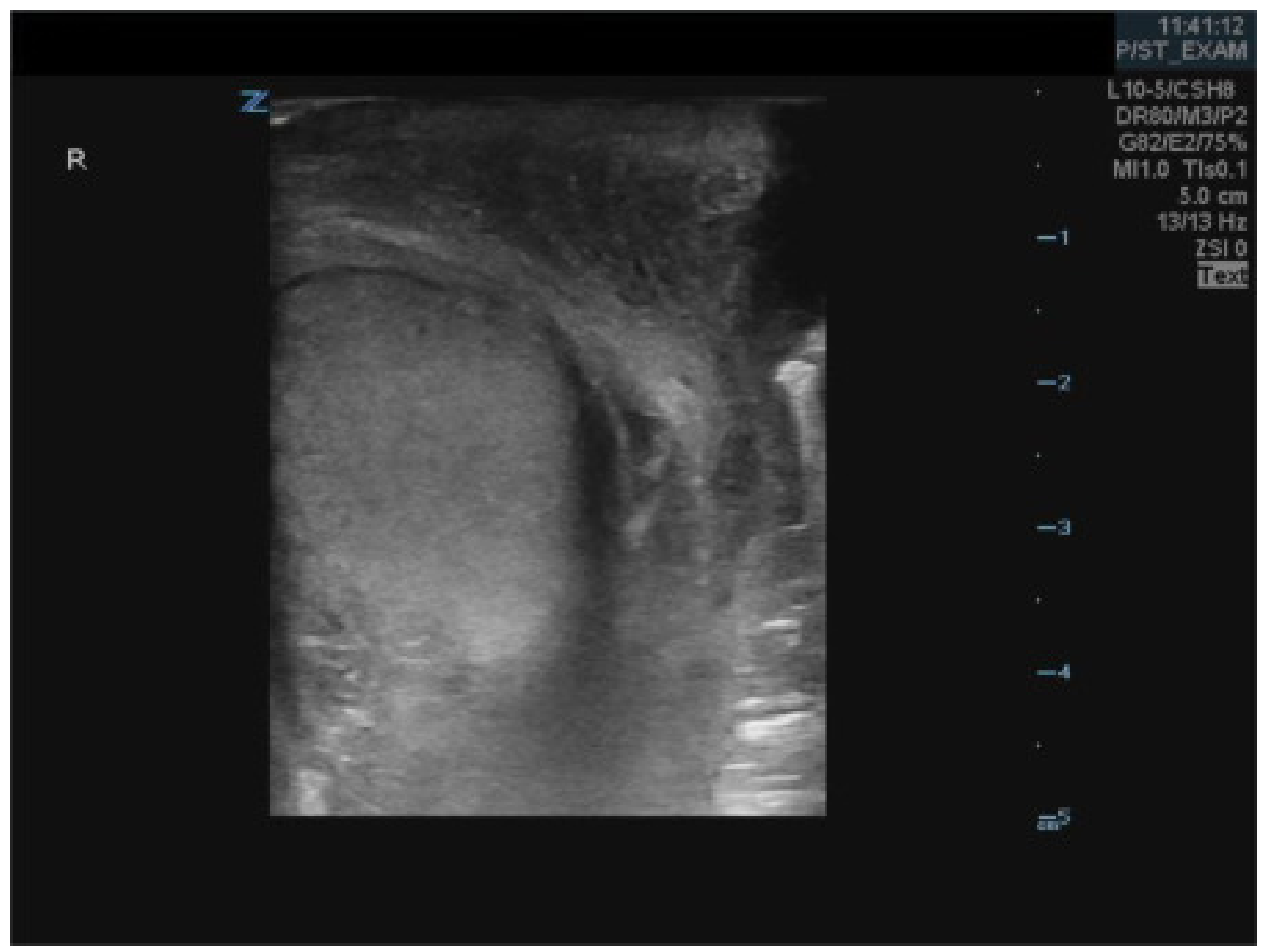

